Portland State University

PDXScholar

7-10-1996

\title{
Speech Understanding in Noise as a Function of Microphone Placement in Hearing Aids
}

Erin Marlene Flowers Hand

Portland State University

Follow this and additional works at: https://pdxscholar.library.pdx.edu/open_access_etds

Part of the Speech and Rhetorical Studies Commons

Let us know how access to this document benefits you.

\section{Recommended Citation}

Hand, Erin Marlene Flowers, "Speech Understanding in Noise as a Function of Microphone Placement in Hearing Aids" (1996). Dissertations and Theses. Paper 5190.

https://doi.org/10.15760/etd.7066

This Thesis is brought to you for free and open access. It has been accepted for inclusion in Dissertations and Theses by an authorized administrator of PDXScholar. Please contact us if we can make this document more accessible: pdxscholar@pdx.edu. 


\section{THESIS APPROVAL}

The abstract and thesis of Erin Marlene Flowers Hand for the Master of Science in Speech Communication: Speech and Hearing Science were presented July 10, 1996, and accepted by the thesis committee and the department.

COMMITTEE APPROVALS:

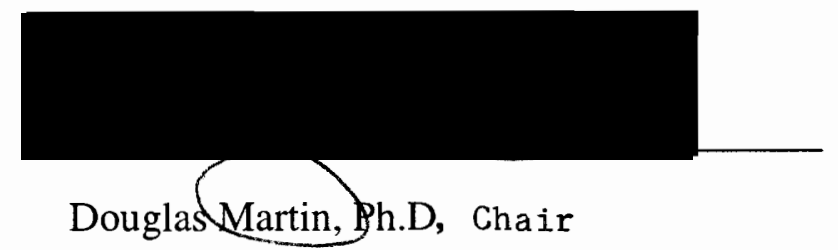

DEPARTMENT APPROVAL:
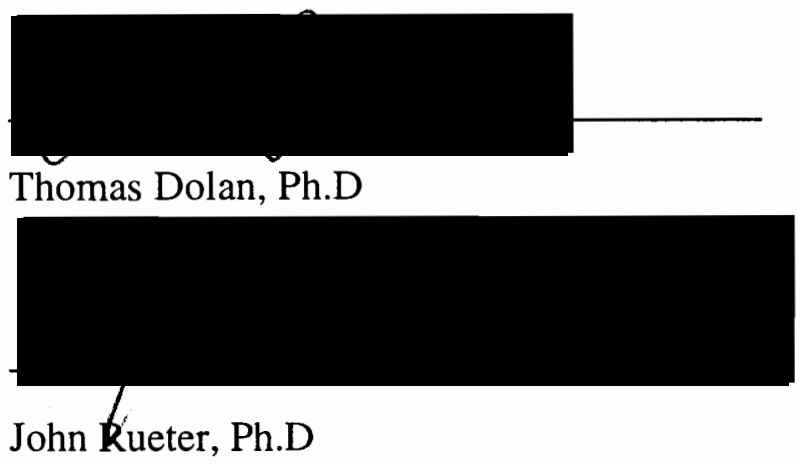

Representative of the Office of Graduate Studies

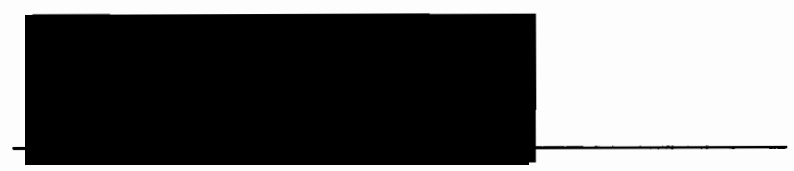

Rhea Paul, Acting Chair

Department of Speech Communication

$* * * * * * * * * * * * * * * * * * * * * * * * * * * * * * * * * * * * * * * * * * * * * * *$

ACCEPTED FOR PORTLAND STATE UNIVERSITY BY THE LIBRARY

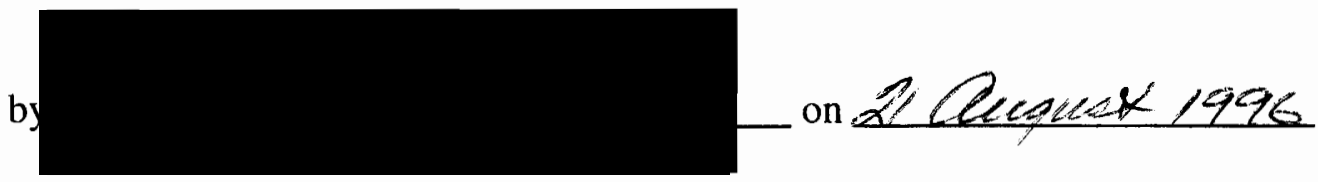




\begin{abstract}
An abstract of the thesis for Erin Marlene Flowers Hand for the Master of Science in Speech Communication: Speech and Hearing Science presented July 10, 1996.
\end{abstract}

Title: Speech Understanding in Noise as a Function of Microphone Placement in Hearing Aids.

Hearing aid users often complain of poor speech understanding in the presence of background noise. There have been many attempts to overcome this problem by hearing aid manufactures and dispensers. The purpose of the present study was to determine if differences existed between three different styles of hearing aids (i.e. in the ear (ITE), in the canal (ITC), and completely in the canal $(\mathrm{CIC})$ ) in the presence of a multi-talker babble.

Five sensori-neural hearing impaired subjects were selected from the Portland State University audiology clinic. The subjects were required to listen to a recording of the California Consonant Test (CCT) against a background noise of multi-talker babble. Stimuli were presented through headphones in the sound booth. The stimuli were recorded through three different hearing aids placed on KEMAR's left ear and adjusted to a $10 \mathrm{~dB}$ signal-to-noise ratio. Once the speech samples were recorded and digitized, they were routed through a GSI-16 audiometer to the listener.

In order to determine performance differences across the three hearing aid configurations from within a single-subject design, each subject's performance was compared in a pairwise fashion between the hearing aid configurations. An analysis of the data was completed using the 
Randomization test. Using this statistical model, no significant difference was found between the individual scores. Further research is warranted to determine if a better measure exists that qualitatively defines the effect of microphone placement on speech understanding ability in hearing aid users. 
SPEECH UNDERSTANDING IN NOISE AS A FUNCTION OF MICROPHONE PLACEMENT IN HEARING AIDS

by

ERIN MARLENE FLOWERS HAND

A thesis submitted in partial fulfillment of the requirements for the degree of

\author{
MASTER OF SCIENCE \\ in \\ SPEECH COMMUNICATION: \\ SPEECH AND HEARING SCIENCE
}

\author{
Portland State University \\ 1996
}




\section{Acknowledgments}

I am greatly indebted to Dr. Doug Martin who not only gave me continued direction and support throughout this study, but through the 2 years I spent at Portland State University. Your encouragement and confidence in me is greatly appreciated.

My gratitude goes to Dr. Tom Dolan whose help was instrumental in the development of the methods for this project. I also appreciate his guidance throughout my education, and his insightful comments which served to clarify my thinking and writing.

I would also like to thank Dr. John Reuter for serving on my thesis committee and providing key suggestions to improve the paper.

I would like to extend my deepest gratitude to Whitney Gearin for all the help he gave me in formating this paper and making my everyday trecks to the computer lab enjoyable.

Finally, my special gratitude and appreciation go to Jeff Nye. Thank you for editing my thesis as well as being an invaluable source of support, encouragement, and advise throughout the thesis process, as well as my entire graduate education. To him, I dedicate this thesis . 
THESIS APPROVAL $\ldots \ldots \ldots \ldots \ldots \ldots \ldots \ldots \ldots \ldots \ldots \ldots \ldots \ldots \ldots$

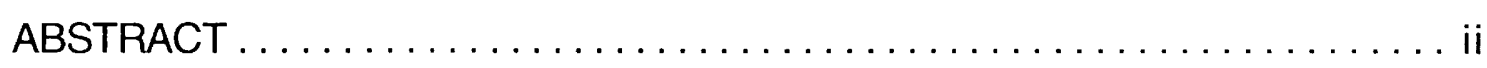

ACKNOWLEDGEMENTS $\ldots \ldots \ldots \ldots \ldots \ldots \ldots \ldots \ldots \ldots \ldots$

CHAPTER

I INTRODUCTION $\ldots \ldots \ldots \ldots \ldots \ldots \ldots \ldots \ldots \ldots \ldots \ldots \ldots \ldots \ldots \ldots$

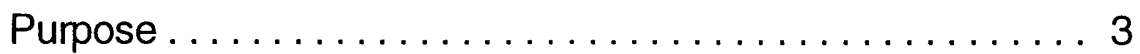

II REVIEW OF THE LITERATURE $\ldots \ldots \ldots \ldots \ldots \ldots \ldots \ldots$

Speech in Noise Problems . . . . . . . . . . . . . . 4

Hearing Aids as a Solution . . . . . . . . . . . 8

Filtering $\ldots \ldots \ldots \ldots \ldots \ldots \ldots \ldots \ldots \ldots \ldots \ldots, 8$

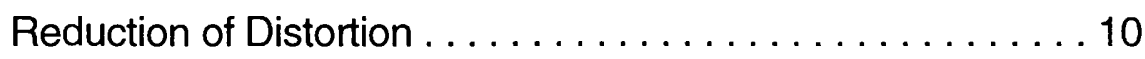

Microphone Effects .................... 14

Testing Speech Understanding in Noise . . . . . . . . 19

Individual Variability with Speech Understanding . . . . . 23

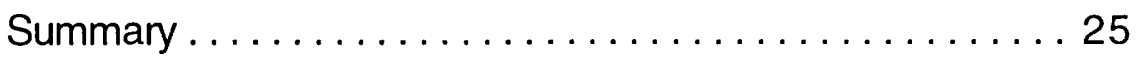

III METHODS .................................

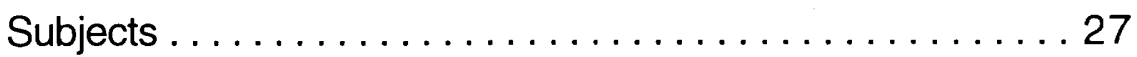

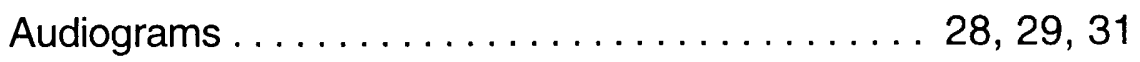

Instrumentation ....................... 30

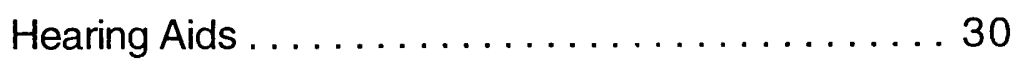

Test Tapes ......................... 30

Coupler Response . ..................... 32

Procedures ............................. 34

Data Analysis .................... 35 


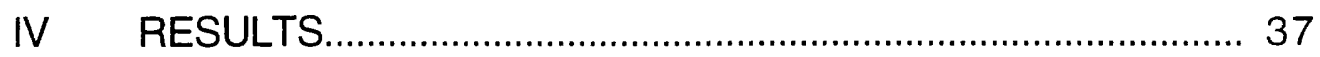

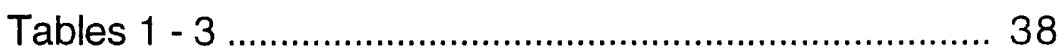

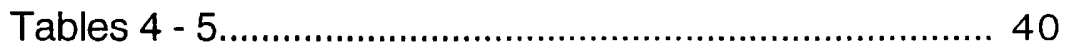

V DISCUSSION AND RESEARCH IMPLICATIONS................ 42

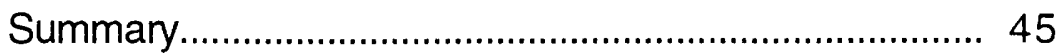

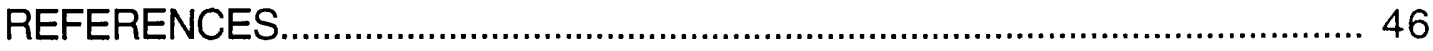




\section{Chapter 1}

Introduction

In our society, most listening situations take place in some sort of ambient noise environment. Whether it be restaurant noise, traffic, music or a combination of voices, the hearing impaired individual is placed at a disadvantage. This is especially true for those with a high frequency sensorineural loss where increasing auditory distractions result in difficulties with speech understanding (Plomp, 1994).

A hearing aid is the most commonly used device to treat hearing difficulties. The function of a hearing aid is to amplify speech to levels above an individual's threshold of hearing. However speech is not the only sound amplified. Because of the complexities of speech and noise signals, a hearing aid designed only to amplify the desired signal is unavailable, thus leading to user dissatisfaction.

A number of studies have investigated speech-to-noise ratio and its relation to the selection, fitting, and use of hearing aids. These studies suggest that hearing aid users are typically not satisfied with their hearing aids performance in noise (Duquesnoy and Plomp 1983). Plomp suggested that top priority be given to discovering ways to improve the speech-to-noise ratio in hearing aids as this is where the most difficulty in understanding speech is encountered.

To improve listener satisfaction with hearing aids, hearing aid manufacturers have attempted various technological approaches to improving the quality of the amplified signal. Microphones with directional characteristics were introduced to the hearing aid market in 1971 and were thought to be a solution to difficulties hearing in noise. Their advantages 
include a modest increase in signal-to-noise ratio as well as improved speech discrimination performance for sounds originating in front of the user (Madison and Hawkins 1983, Lentz, 1972). Beck (1983) found that a carefully engineered directional microphone will give sounds from the front a $3 \mathrm{~dB}$ increase in intensity. This is helpful for people who are often in situations where sounds occur primarily in front of them (classroom), but will provide limited benefit for those who need to hear sounds from all around (e.g., taxi cab drivers). Lentz (1972), however, reviewed a number of studies involving directional microphones and concluded that many of the advantages would not be present in more reverberant environments.

A second microphone - related characteristic which may impact performance involves the actual location of the microphone. While a number of studies examining effects of microphone location have been reported, few have examined the effects of speech understanding in noise solely as a function of microphone location. Skinner (1988), examined the effect of microphone placement in body aids, eyeglass, behind-the-ear (BTE), in-theear (ITE), and in-the-canal (ITC) hearing aids. She described the microphone placement in a behind-the-ear hearing aid as beneficial in that the top location gave better reception of sound as compared to eyeglass or body aids. An enhancement by $5 \mathrm{~dB}$ in an in-the-ear hearing aid was attributed to the microphone location with microphone placement deeper into the concha, the natural resonating characteristics of the external ear will modify the input to the hearing aid by enhancing signals between 1500 and $4000 \mathrm{~Hz}$. A slightly larger increase in high frequency gain was noted in the ITC aid, due to a deeper microphone placement within the ear canal. This style of aid can take advantage of changes in sound at the microphone as the head is moved, thereby exploiting natural resonating characteristics of 
the ear and improving localization (Chasin 1994). The pinna may enhance 3 speech understanding in noise because of this boost in gain at the frequencies centered around speech. As noise increases, energy in the low frequencies increases making it difficult for those with a high frequency hearing loss to use their residual hearing. Taking advantage of the pinna by wearing an in-the-ear hearing aid, will theoretically increase the output in the frequencies from 1500 to $4000 \mathrm{~Hz}$, thereby making speech understanding in noise easier (Teder, 1991).

Statement of Purpose

The purpose of this study is to investigate the effects of microphone placement on speech intelligibility in noise. This was accomplished by having hearing impaired listeners perform a speech understanding task using three different styles of hearing aids. 
Chapter 2

Review of the Literature

When evaluating the effect of microphone placement on speech understanding in noise, a number of specific issues must be considered. It has been well documented that speech discrimination problems in noise exists (Cox and Alexander 1991, Kamm, Dirks and Bell 1985, Pavlovic 1984, Mueller 1995) and there have been numerous attempts to overcome it (Sweetow 1989, Villchur 1973, Graupe and Causey 1977, Widrow 1975). In support of this study, it is important to understand the effects of noise on speech understanding and to what degree microphone characteristics of the device contribute to the solution. A further issue of concern regards documenting changes in speech understanding under various listening conditions. The current literature examines these two issues separately (Cox and Alexander, 1991, Mueller 1995), however, the interaction between microphone placement and speech understanding in noise has not been fully investigated (Fortune and Preves, 1994).

I. Speech in noise problems

Problems understanding speech in noise have long been the most frequent complaint of hearing aid users (Cox and Alexander, 1991). Much of the noise problem in hearing aids is due to saturation of the hearing aid caused by moderate to high levels of background noise input signals (Franks and Beckmann, 1985). Crowd noise is the most common and most difficult environmental noise hearing aid users face. In addition to this problem, a reflexive increase in speech effort, termed the Lombard voice reflex (Van 
Summers, Pisoni, Bernacki, Pedlow, and Stokes, 1988) causes increased vocal effort with increased noise. This contributes to a more difficult environment for understanding speech. A hearing aid will make sounds louder and, in a noisy situation, the loud environmental sounds drive the hearing aid into saturation, reducing $\mathrm{S} / \mathrm{N}$ ratio and subsequently, discrimination. (Van Summers et al, 1988).

Cox and Alexander (1991) investigated hearing aid benefit in everyday environments. Three matched groups of eleven hearing impaired subjects were evaluated. Benefit was quantified using the Connected Speech Test, (CST) to determine improvement in intelligibility. This test, composed of 10 sentence passages about common topics, is presented to the listener with competing six-talker speech babble. The subject is informed of the topic matter, instructed to listen to the sentence, then repeat back as much as he/she understood. Each subject was placed in 3 different everyday listening environmental situations:

A) speech at normal conversation level (55 dB Leq) (Leq = equivalent continuous $\mathrm{dBA}$ level) with multitalker babble at $48 \mathrm{~dB}$ Leq;

B) an environment with low external noise (55 dB Leq) and speech (66 dB Leq) which was degraded due to reverberation, and;

C) a noisy environment where background noise levels equaled 62 $\mathrm{dB} \quad$ Leq and speech levels were $64 \mathrm{~dB}$ Leq. It was shown that mean benefit in a living-room type setting was about $24 \%$, in a reverberant setting was $7 \%$, and in a noisy setting was $-1 \%$. The overall results of this study indicate no statistically significant difference between benefit in conditions $\mathrm{B}$ and $\mathrm{C}$, however, there did prove to be a difference in condition $\mathrm{A}$. 
This difference between environments $A$ and $B / C$ could be attributed to a combination of factors. One major factor was the more favorable signal to babble ratio (SBR) in condition $A$ than that of conditions $B$, or $C$. The unfavorable results obtained in environment $B$ were undoubtedly due to the temporal smearing of speech that resulted from reverberation. Although the signal in condition $\mathrm{C}$ was audible, it may not be fully comprehended in individuals with a sensorineural impairment.

The overall findings showed a difference in speech understanding in condition A, but not in B or C (Cox and Alexander, 1991). This is somewhat disturbing for clinicians because 1) clinical and laboratory tests show that some benefit is achieved in noisy environments and 2) several investigations have shown that improved audibility is usually consistent with improved intelligibility (Kamm, et al., 1985, Pavlovic, 1984).

This study, similar to the present study, attempts to document speech understanding as a function of signal-to-noise ratio. The results of this study are disputed by some (Cox and Alexander, 1991) as they believe poor speech understanding is due to factors other than signal-to-noise ratio. These include:

A) the failure of hearing aids to amplify speech to audible levels or;

B) the inability of hearing impaired persons to differentiate between the signal and the noise (Cox and Alexander, 1991).

An interesting study dealing with the redundancy of speech cues for better understanding in noise was conducted by Villchur (1973). He suggests that the attention mechanism is central rather than sensory and therefore requires repetition of speech cues to overcome masking problems. In his study, six subjects were scored under three conditions; 1) linear 
amplification in the presence of interference (reference), 2) linear amplification in quiet, and 3) processed amplification with interference. The term processed amplification refers to restoring speech cues by 2-channel amplitude compression combined with frequency-response shaping. The results of this experiment showed that four of six subjects benefited more from processing to restore speech cues than from removing the interference entirely. In summary, Villchur suggests that the most important task for hearing-aid designers and clinicians is, through the use of hearing aids and aural rehabilitation, to restore the hearing impaired person's ability to perceive acoustical speech cues they have lost. In doing this, it would make possible the task of separating desired from undesired speech signals (Villchur, 1973).

An important factor to consider when studying the effects of noise on speech understanding is the type of noise present. Mueller (1995) suggests that when the background noise is primarily low frequency it is possible to understand speech better than if the background noise is speech and, subsequently, covers a broader frequency range. On the average, we speak at about $55 \mathrm{~dB}$ SPL. However, when background noise increases, there is a change in spectral distribution of speech energy, thereby degrading the signal to noise ratio (Mueller, 1995). This is due to an increase in vocal effort causing the peak in the speech spectrum to shift downward, losing high frequency energy. Most normal hearing individuals can follow a conversation when the $S / N$ ratio falls into the $0 \mathrm{~dB}$ to $-5 \mathrm{~dB}$ range, however, most hearing impaired people cannot (Mueller, 1995). For example, if the average speech level in a cocktail party is $55 \mathrm{~dB}$ SPL, and the background noise is $45 \mathrm{~dB} S P L$, there would be a signal - to-noise $(\mathrm{S} / \mathrm{N})$ ratio of $10 \mathrm{~dB}$. 
However, if the background noise increased to $60 \mathrm{~dB} S P L$, the $S / N$ ratio would change to be $-5 \mathrm{~dB}$ SPL, causing difficulties for the hearing impaired person, but leaving the hearing individual with minimal problems.

II. Hearing aids as a solution

Although many hearing aids help wearers hearing in noise, no hearing aids, including advanced laboratory digital signal-processing hearing aids, have the capability to filter out competing speech noise (Killion and Villchur 1993). To combat this problem, many noise reduction devices have been incorporated into today's hearing aids. Each of these devices may help to reduce the problems of understanding speech in noise, but none are able to overcome it. Development of new and improved amplifier types, the introduction of compression circuitry and the use of directional microphones have all attempted to improve speech understanding in noise.

Filtering

Traditional approaches to reducing noise involve adjusting low frequency gain through electrical or acoustical modifications. These solutions are based on the observation that most noises are low frequency dominated. A problem with this approach lies in differential amplification of high vs. low frequencies causing a "tinny" sound quality when too many low frequencies are cut (Sweetow, 1989). Danaher and Pickett (1975) looked at the fundamental principles behind today's noise reduction circuitry. They found most approaches to enhancing speech perception in noise involved changing the hearing instruments' gain in the lower frequencies. They are assuming then, that 1) background noise is primarily low frequency in spectral content and, 2) poor speech understanding may be due to excessive low frequency amplification which may mask the mid to high frequencies 
(Danaher et al, 1975). To reduce this problem of poor sound quality, adaptive hearing aid circuits have been designed to automatically change the low frequency response by estimating the amount of low frequency energy present. This adaptive frequency technology includes such devices as: multi-channel compression (Villchur 1973), multi-channel adaptive filters, and adaptive high pass filters (Graupe et al, 1980). The idea behind these circuits is to automatically compress the low frequency energy, leaving the critical high frequencies to be amplified for speech understanding (Kates, 1988). Killion (1990) developed the TILL (treble increase at low levels) circuit which also proved useful in noise reduction.

Mueller (1993) discussed 4 types of automatic signal processing (ASP) or compression circuits. Two involve advanced filtering techniques. The BILL (base increase at low levels) circuitry seems most successful when the background noise is low-frequency dominate. The BILL decreases the low-frequency gain when low frequency sounds become intensified. In essence, it becomes a high pass filter in the presence of intense signals. The TILL processor has just the opposite effect. For quiet sounds, the processor increases the high frequency gain aiding with speech understanding in noise. Currently, the K-AMP, designed by Mead Killion, is the most popular TILL circuit available (Mueller 1993).

Graupe and Causey (1977) introduced the zeta noise blocker (ZNB) which was packaged small enough to fit into an ITE. This device attempted to sample noise levels during the silent intervals of speech. Unfortunately, the ZNB has not gained widespread success in hearing aid technology despite its availability from a number of manufacturers. This may be due to 
the sensitivity of the circuit producing large changes in frequency response that were irritating to the listener.

Automatic gain control circuitry has been utilized by various manufacturers and their effectiveness has been measured extensively (Dempsey 1987, Stach, Speer, Schneider, and Jerger 1987, Stein and Dempsey-Hart 1984, Van Tasell et al 1988, and Wolinsky, 1986). The general finding is that although some hearing impaired individuals received improvement in speech recognition, the benefits were minimal (Kuk, Tyler, Stubbing and Bertschy ,1989).

\section{Reduction of Distortion}

In an attempt to reduce the distortion in hearing aids, a variety of circuitry options have been developed (Pollack, 1987, Preves and Newton, 1989, Knowles 1988, Mueller, 1993). The amplifier in the hearing aid is one area that has undergone modifications. Currently, three types (or classes) of amplifiers are available: class $A$, class $B$, and class $D$. Class $A$ is a linear amplifier. With a linear amplifier every $1 \mathrm{~dB}$ increase in input, leads to a $1 \mathrm{~dB}$ increase in output until saturation levels are reached. At saturation levels, an increase in input leads to an increase in distortion (Pollack, 1987). The problem inherent in this circuit is the peak clipping that occurs when high input signals are introduced resulting in distortion of the signal. Smriga (1985) indicates that the introduction of distortion and the loss of input content in the output results in reduced intelligibility of speech.

The second amplifier developed, the Class $B$, is most frequently used when more power is needed. This amplifier utilizes a push-pull configuration where there are at least two active devices that alternately amplify the 
negative and positive cycles of the input waveform. Because they consume almost no current when no sound is entering the aid, they use less battery power than a class $\mathrm{A}$ and are therefore more efficient. This amplifier has the theoretical capability of providing up to four times more output signal amplitude in a hearing aid receiver as compared to the single-ended class $A$ amplifier (Preves and Newton, 1989).

The third class, the Class D amplifier, has gained considerable popularity in the hearing aid market since its introduction in 1988 by Knowles. This system minimizes peak clipping due to its wider dynamic range and limited distortion prior to saturation level (Pollack, 1987). The difference in perceived sound quality can be attributed to the greater headroom (saturation level - (gain + input)) provided by the Class D amplifier (Longwell \& Gawinski, 1992).

Mueller (1993) discusses compression limiting and wide dynamic range circuitry as output features that attempt to improve the speech signal. Compression limiting circuitry employs a high compression threshold and a high compression ratio. It attempts to decrease the amount of intermodulation and harmonic distortion that occurs when an aid is driven into saturation. This is accomplished by placing a ceiling on the output of the hearing aid. Compression limiting is viewed as an alternative to peak clipping. This technology allows more of the input signal to be present in the output signal (Pollack, 1987). Compression, or automatic signal processing (ASP) devices are one attempt at increasing the signal to noise ratio for better understanding of speech.

The next type of ASP circuit Mueller discusses is the wide dynamic range. The basis of this circuitry is to place the entire dynamic range of 
speech into the patients reduced range. To successfully do such a task, the aid must have a low compression knee point and a low compression ratio. Ideally this should make soft speech audible, but refrain from causing loud sounds to become painful.

A study conducted by Bentler (1993) studied the effectiveness of different noise reduction (NR) circuitry's including adaptive compression. Two groups, $A(n=43)$, and $B(n=15)$, were followed closely over one year. Participants in group A were fit with one of 4 types of noise reduction circuits (Zeta, adaptive low-frequency filtering, adaptive compression, or frequency dependent input compression). Subjects in group B had linear circuits or circuits with compression limiting only. Results indicated that only 4 individuals in group A perceived themselves as receiving benefit from the noise reduction circuit. These data were found not to be statistically significant using a one-way analysis of variance (Bentler, 1993).

Kuk et al, (1989) conducted a study to determine if hearing impaired listeners perform better using a hearing instrument with noise reduction than using the same hearing instrument without the noise reduction. The amount of low-frequency gain was the differentiation factor between the two versions of noise reduction circuits ( $6 \mathrm{~dB} /$ octave roll-off and $12 \mathrm{~dB} /$ octave roll-off). The noise reduction in each circuit could be turned on and off. The results showed that $80 \%$ chose the instrument with the noise reduction circuit for their daily use. Among those, $70 \%$ chose the $6 \mathrm{~dB} /$ octave roll-off version. The subjective evaluation, however, showed the NR was beneficial in mildmoderately noisy environments, but was of minimal use in loud, noisy situations (Kuk et al., 1989). 
Noise reduction circuits are one method of overcomming a poor signal-to-noise ratio, however, as Villchur (1973) suggests, perhaps enhancing the signal is a more effective way to improve speech understanding. The introduction of $\mathrm{CIC}$ hearing aids requires less amplifier output because of its position in the ear canal. This device provides a higher saturation sound pressure level (SSPL) relative to other hearing aid devices and is specific only to aids with a long canal terminating at the bony portion of the ear canal. Long canals, most often found in $\mathrm{CIC}$ aids, leads to a reduction of distortion due to decreased amplifier output. This is possible because less amplifier gain is required to power the aid. Less gain will decrease the occurrence of saturation or induced distortion (Mueller, 1994). When the aid is fit deeper into the ear canal, the residual volume between the tip of the hearing aid and the tympanic membrane is decreased. The smaller the residual volume, the greater the SPL at the eardrum. Gudmundsen (1994) measured the output to be as much as 19-21 dB greater than the output measured in a 2-cc coupler.

Greater headroom obtained in a CIC results in less saturation of sound which in turn increases sound quality of the hearing aid. In noisy situations, increased headroom will likely result in an increased uncomfortable listening level (UCL) for the user because there is less distortion for high input levels (Gudmundsen, 1994). Agnew (1994) describes how the physical location of a $\mathrm{ClC}$ aid causes reduced residual air cavity between the tip of the hearing aid and the tympanic membrane. This area, referred to as $V 3$, is the reason less gain is needed to boost sounds to audible levels. Agnew goes on to state,

Theoretically, every time $\mathrm{V} 3$ is halved, the sound pressure 
at the tympanic membrane is increased by $6 \mathrm{~dB}$. While $\mathrm{V} 3$ for a typical ITE fitting might be on the order of $1.0 \mathrm{cc}$, it may be only $0.25 \mathrm{cc}$ for a deeply-inserted $\mathrm{CIC}$ aid. This reduces V3 by fourfold, which results in a potential gain increase of $12 \mathrm{~dB}$ for the $\mathrm{CIC}$ aid just due to the $\mathrm{V} 3$ cavity-size reduction (Agnew, 1994 p. 22).

His study showing increases in gain with decreases in residual volume using a Starkey tympanette as measured on KEMAR show that a 20 $\mathrm{dB}$ peak gain can be achieved with a 2 cc coupler whereas gain measurements of up to $45 \mathrm{~dB}$ were measured with each reduction in V3. As insertion into the canal becomes deeper, a similar effect, labeled V4, is observed. V4 refers to the air-filled middle ear space and its relation to an increase in high frequency amplification. Because of reduced compliance of the eardrum as frequency increases, the contribution of V4 with respect to V3 decreases with increasing frequency, giving high frequency sounds increased amplification (Agnew, 1994).

\section{Microphones Effects}

Another approach to the problem of speech understanding in noise involves the use of directional microphones. Most hearing aids are equipped with microphones that are equally sensitive to sounds in all directions. A new technology introduced to hearing aids, attempted to reduce signal-tonoise ratio through the use of a directional microphone. Two separate sound ports, one facing the front and one facing the rear, were designed to minimize sound from behind and enhance sound from the front. This can occur because the rear port has a built in delay of about 58 usec. Sound occurring behind the person will arrive at the opposing faces of the diaphragm of the microphone simultaneously, and consequently will be canceled (Lybarger 1985b). Beck (1983) found that a carefully engineered 
directional microphone will give sounds from the front a $3 \mathrm{~dB}$ boost in intensity. This characteristic will greatly benefit those in situations where the sound source is in front. The problem, however, is with individuals who wish to hear sounds from all directions equally. Lentz (1972) found a modest increase in signal-to-noise ratio as well as improved speech discrimination for sounds originating in front of the user. He also reviewed a number of studies that demonstrated no significant improvement in speech understanding with directional microphones in reverberant environments.

Sung, Sung and Angelelli (1975) suggested that further studies be conducted on the directional microphone that allows the user to switch the directional effect on or off. This recommendation was a result of a study they completed on the directionality of different brands of microphones. They reported an improvement in speech understanding in noise with the use of directional microphones, however, they recommend careful evaluation of intersubject performance before suggesting such an aid (Sung et al. 1975).

Another attempt to alleviate noise, adaptive noise canceling, was proposed by Widrow et at (1975). This device makes use of two or more microphones in the same housing or a microphone in each side of a binaural hearing aid fitting. With this technology, a reduction in excess of $20 \mathrm{~dB}$ of noise can be achieved. This was thought to be possible by having the same noise signal in both microphones, but to have speech only in the primary microphone. Unfortunately, the reference microphone output would contain some speech as well as noise causing partial cancellation of speech (Weiss, 1987).

The beamformer, as described by Farassopoulos (1989) is another attempt to solve problems with speech in noise. The idea behind this is 
similar to the directional microphone however the beamformer has the ability to adapt to changes in the direction of the undesirable noise source. This technology consists of two or more microphones which, in combination with adaptive filter, produces sharp nulls in output in the direction of noise. The problem lies in the packaging of this circuit, as it requires direct wiring of the microphones to the digital filter. Unfortunately, the beamformer can not be integrated into conventional hearing aids because of space limitations (Preves, 1993).

Another variable which must be considered is the location of the microphone on the hearing aids. The development of $\mathrm{CIC}$ aids has led to much discussion regarding the effects of microphone placement and the resulting acoustic benefits. Mueller (1994) lists 16 potential advantages of $\mathrm{ClCs}$, some of the most important being, increased gain caused by the natural resonating characteristics of the pinna, and reduced distortion due to decreased output as a result of reduced residual volume (Mueller, 1994).

The acoustic characteristics of the outer ear are an important factor to consider when examining the microphone placement and its effect on the speech signal. The pinna was originally thought to be a vestigial organ useful to humans purely for cosmetic reasons (glasses, earrings). It does however, serve a critical function in sound localization. The convolutions of the pinna reflect and resonate different sound sources before filtering them into the external canal. This filtering by the pinna plays a major role in the localization of sound as well as externalizing sound, which is the perception of localizing sound outside the head (Agnew, 1994). This is the first complex process of many that sound goes through before being processed as useful information. As well as using the convolutions to direct sound, the pinna also 
serves as a baffle to assist in front and back localization. The $2000 \mathrm{~Hz}$ region is especially sensitive to the reflection of the pinna with a 4-8 $\mathrm{dB}$ increase with frequency being measured by Hosford-Dunn (1996).

Another function of the pinna described by Agnew (1994) is in the interaural time differences and interaural amplitude differences in sound and their function in localization. The physical dimensions of the head cause sound to reach each ear at slightly different phases helping to localize sound in the horizontal plane. As well, interaural time and amplitude differences have been shown to improve signal to noise ratio in noisy environments due to head baffle effects in turn increasing speech intelligibility in noise (Agnew 1994).The benefit of a deep canal hearing aid is that the concha remains unoccluded and these pinna effects can be utilized.

In 1994, Chasin examined the natural resonance effects of the pinna and found that frequencies of $2000 \mathrm{~Hz}$ and above were most enhanced. Because it is a reflective surface for shorter wavelengths, the lower frequencies pass through relatively unaffected. The measured amount of the pinna effect is dependent on the location of the measurements taken. When measured at the microphone of an ITE instrument, the effect is minimal compared to that of a deep canal instrument where pinna effects can be 3 times as great (Chasin, 1994). Shaw (1974) and Northern, Kepler, Gelnett, Sillivan, Soli, and Goldberg, (1992) also looked at the resonance effects of the ear. In different studies, they discovered the pinna and concha provide a 6-8 dB gain at frequencies of between $4000-5000 \mathrm{~Hz}$, causing sound occurring at these frequencies to be enhanced before hitting the tympanic membrane. Killion (1993) notes that the middle ear system has a higher 
compliance for low frequencies, therefore the SPL will increase for the high frequencies, similar to a high pass filter.

Skinner (1988) looked at the effect of microphone placement in eyeglass, body, BTE, ITE, and ITC hearing aids. She describes the microphone placement in a BTE hearing aid as beneficial in that the top location gives better reception of sound as compared to eyeglass or body aids. An enhancement by $5 \mathrm{~dB}$ in an ITE hearing aid is attributed to the microphone being located in the pinna thereby enhancing sound between 1500 and $4000 \mathrm{~Hz}$. A canal aid is even more efficient delivery by increasing an even wider frequency range. Between 1500 and $6000 \mathrm{~Hz}$, the sound is increased by as much as 5-10 dB. This type of aid can also take advantage of changes in sound at the microphone as the head is moved, improving localization.

In a study conducted by Fortune and Preves (1994) five subjects were studied in terms of the effect microphone placement had on wind noise. A common problem for hearing aid users is not only competing speech noise such as in a restaurant, but also environmental noise such as wind. Speech understanding in vehicles is difficult for the hearing aid user because of the competing mechanical and environmental noises. A 4-inch "squirrel cage" blower was used to simulate wind noise which was analyzed to be acoustically dominated by low-frequency energy. A Knowles EM 3046 ITE, ITC and CIC was constructed for each participant with the differences laying only in microphone placement. The results of this study showed equal amplification of wind noise in an ITE coming from all directions. The canal aid showed much the same response, however the $\mathrm{CIC}$ aid showed significant minimization of wind noise. The wind-noise advantage of a deep 
canal aid provided a $7 \mathrm{~dB}$ advantage to that of the ITE (Fortune and Preves 1994).

IV. Testing Speech Understanding in Noise

Quantifying improvement from hearing aids is an important part of dispensing the device. Real ear measures are frequently used as an objective measure to numerically show target match to a specific fitting formula. Utilizing aided sound-field scores at the time of fitting is another option to quantify improvement from hearing aids (Fabry and Schum, 1994).

There is however, some controversy regarding the use of speech testing as a method for measuring hearing aid benefit. Walden, Schwartz, Williams, Holum-Hardegen and Crowley (1983) conducted a study examining hearing aid evaluations. Differences in speech understanding abilities was compared over six ear-level hearing instruments in 55 adult males. They discovered that when attempting to quantify improvement using the NU-6 test list, no significant differences were found between aids with similar electroacoustic characteristics. They suggest that using monosyllabic word lists is an inadequate measure for comparing hearing aid devices.

Gatehouse and Killion (1993) propose a theory in which they advocate allowing the user 6-12 weeks to "get used to (the hearing aid)" before conducting subjective speech understanding tests. They hypothesize that, "rather than exhibiting a mere "getting used" to the aid, there is a fundamental perceptual process where the brain requires some "rewiring" (Gatehouse and Killion, 1993). These authors state,

When presented with a range of speech information which had previously been unavailable, it can take considerable time to learn to make optimum use of the new set of speech cues and thereby derive optimal benefit from the amplification... when 
the hearing impaired individual is provided with amplification...then the previously inaudible areas of the auditory world now become audible and are presented to the brain. However, the areas that were previously used for coding the higher frequency, low intensity signals, have now been reallocated to other frequencies and intensities, and it make take a considerable period of time for this re-rewiring...to take place (Gatehouse and Killion, 1993 p. 32)

In a similar study, benefits could not be initially determined in individuals who were receiving minimal information above $2500 \mathrm{~Hz}$. The real benefit only started to become apparent after experience with the hearing aid of up to 6 weeks (Gatehouse, 1992). Cox and Alexander (1991) showed that both perceived benefits of amplification and measured speech identification abilities can increase across a three month time period. Because most high frequency sensorineural loss is progressive taking place over a number of years, the brain will begin to compensate for lost information. The high frequency information will be re-allocated by the brain (Gatehouse and Killion, 1993).

Killion and Villchur (1993) described a prerecorded test that helps to document speech understanding benefit in noise. This was in response to a claim made by a hearing aid manufacturer that Food and Drug Administration Commissioner David Kessler, MD questioned in 1993. The manufacturer's claim suggested that certain hearing aids could reject the noise the listener did not want to hear. The confusion about noise rejection circuits is warranted and prompted Killion and Villchur to respond by providing a simple test named the speech in noise (SIN) test to record such improvement. The test consists of two 40 - sentence test blocks for aided and unaided comparison. Each subject was evaluated on an individual basis and the results showed that class D circuits, "improved the intelligibility of low-level-speech in low-level-noise and they don't degrade high-level- 
speech in high-level-noise" (Killion and VIllchur 1993, p.34)". A number of tests attempting to produce valid and reliable measures of speech understanding in noise have been developed such as the Hearing in noise test (HINT), and the California Consonant Test (CCT).

The HINT test was designed by Soli and Nilsson (1994) as an attempt to measure the best ability of the individual to hear in noise. It is an adaptive measure of speech reception threshold for use in quiet or noise. This test eliminates ceiling and floor effects which are usually associated with speech measures. Unlike other speech-in-noise tests, the HINT does not allow the individual to use their binaural directional hearing ability. Instead, the speech-weighted noise is specially separated from the source of the speech (Nilsson, Gelnett, Sillivan, Soli and Goldberg 1992, Nilsson Sullivan and Soli 1991, Nilsson, Hoffman, Buckley, and Soli,1990). This is rationalized because in most environments, the listener will often attempt to achieve the same type of spatial separation by orienting toward the speech and away from the noise. A 6-7 dB average increase in speech reception thresholds was found due to spatial separation. This corresponds to intelligibility improvements of $50-60 \%$ (Nilsson, Soli and Sullivan, 1994).

The California Consonant Test (CCT) has also been developed to quantify speech understanding in noise. Owens and Schubert (1977) developed this test to assess phonemic confusions of those individuals with a hearing impairment. They state that, "a clinical test should be developed which permitted phoneme variation in only one position in any given item, which employed an easily manageable number of foils, and for which test format and standardization were dictated by results on the clinical population for whom it was intended "(Owens and Schuber 1977, p. 464). The materials 
for this test were selected from a pool of over 400 multiple-choice items and divided into seven test forms. The reported findings on the first five test forms indicate the following;

(1) hearing-impaired patients make relatively few voicing errors in consonant recognition on this test format and they seldom confuse nasal with non nasal consonants; (2) consonant confusions involve both place and manner of articulation; (3) several consonants are too easily recognized to be useful as test stimuli, and a few cannot be employed because the language does not afford appropriate alternative choices (foils); (4) four foils for each item seems comfortable for patients; (5) a forcedchoice response procedure is indicated in that subjects generally failed to use a question mark that had been offered as a fifth possible response for each item; (6) confusion between $/ \mathrm{f} /$ and $/ \mathrm{th} /$ is such that when either is the stimulus consonant, the other member of the pair should not be included among the foils (the same holds true for $/ \mathrm{v} /$ and $/ \mathrm{th} /$; (7) items testing final- and initialconsonants contrasts may be interspersed on the same form with no apparent detrimental effects on subject responses; and (8) most consonants are recognized more easily in the initial than in the final position (Owens and Schubert, 1977. p. 465)

The results of this test show three distinct conclusions. The first being that test-retest reliability for 56 subjects taking the test twice in succession was 0.91 with no consistent evidence appearing for either fatigue or learning effect. The second conclusion was that this test also seemed sensitive for high frequency losses in that the mean scores showed a correspondence with progression of loss. The third was the reliability of the CCT is high and it has an appropriate range of difficulty (Owens and Schubert, 1977).

To determine the effect of noise on consonant identification, Givens and Jacobs-Condit (1981) conducted a study using the CCT with normal hearing and sensorineural impaired listeners. In the normal population, they found that consonants in the initial position were easier to identify than in the 
final position. As well, errors occurred consistently in manner and place of articulation, but not in voicing. These data are consistent with Owens and Schuberts (1977) findings in that relatively few errors are made by hearing impaired subjects in the area of voicing. The normal listeners did well with a $\mathrm{S} / \mathrm{N}$ ratio of +20 , but slowly decreased in performance with decrease in $\mathrm{S} / \mathrm{N}$ ratio. They found in the hearing impaired population, a difficulty in identifying phonemes in quiet and in noise. In comparing the two groups, it was found that normals do better in quieter situations, however as noise increases, normals had an increasingly difficult time in distinguishing phonemes. It was suggested through this study that the CCT is sensitive to communication difficulties of the sensorineural impaired individual. The authors recommend this test be used in the clinic in quiet only, or with a $10 \mathrm{~dB} S / N$ ratio because statistically significant differences were found in normals in quiet and with $\mathrm{S} / \mathrm{N}=10 \mathrm{~dB}$. As well, significant group differences existed in both quiet and with $S / N=10 \mathrm{~dB}$ (Givens, and Jacobs-Condit, 1981).

Owens (1978) conducted a study to measure the effects of the distortion using the CCT produced by a hearing loss on consonant recognition. All testing was done in quiet, and the type and frequency of errors, as a function of hearing loss, were recorded. They found that types of errors were consistent between hearing loss configuration. They also suggest that this test is helpful in identifying errors and using that information to develop an aural rehabilitation plan for effective communication (Owens, 1978).

V. Individual Variability with Speech Understanding

Because of individual differences in ability to understand speech in noise, there has been some difficulty quantifying speech understanding in 
noise. In 1992, Parizet and Polack conducted a study with the goal of evaluating the influence that early reflection has on speech intelligibility in noise. Their conclusions showed that the influence of reflection is very listener-dependent and they were unable to determine why, for some listeners, the perception of place of articulation can change. They summarized that this effect depends on the words, the speaker and the listener (Parizet and Polack, 1992).

Cox and Alexander (1991) conducted a study to determine hearing aid benefit in everyday environments. Each subject was fit with three hearing aids differing only in slope and were evaluated in three different listening environments. The three matched groups of eleven hearing impaired subjects showed there to be no significant benefit between the three different hearing aids in everyday environments. However, when considered on an individual basis, $76 \%$ of the subjects achieved significantly different benefit in at least one hearing aid condition (Cox and Alexander, 1991).

Because of significant individual differences among hearing impaired listeners, it may be most appropriate to evaluate speech understanding in noise on an individual basis using a single subject design (Jerger and Chimel, 1995). This research design allows for a controlled condition to determine the performance of a few subjects, and then estimate the effect on a specific population.

Single subject designs are based on individual subject's performance under different conditions. In this way we are able to establish a causal relationship between the ability to understand speech in noise and the placement of the microphone. We are also able to identify individual 
differences by examining each individual and their error patterns (Owen, Owen, Pannbacker and Middleton, 1994).

Chmiel and Jerger (1995) described a statistical procedure called the Randomization Test formulated by Edgington (1967) and more recently by Barlow and Hersen (1984). This test is used specifically for analyzing individual differences in performance. The Randomization Test is especially useful for determining benefit of new hearing aid design for individual patients. This is apparent to Stein, McGee and Lewis (1989) who stated, "hearing aid technologies tend to benefit some, but not all hearing aid users." Evaluating group performance is useful when attempting to determine if a particular design or circuit is valuable on an overall level, but it does not determine individual patient performance. Chmiel and Jerger (1995) demonstrated the efficacy of this procedure using five clinical patients and various materials for quantifying speech understanding. The randomization test is distribution free and is ideal for the evaluation of how various conditions, such as microphone placement, effect speech understanding in the hearing impaired individual.

\section{Summary}

A review of the literature demonstrates there have been many tests evaluating speech understanding in noise, but few have examined the effects of microphone placement. Villchur (1973) suggests that instead of attempting to remove signal interference, it may be more beneficial to try to restore lost speech cues. Instead of the removal of competing noise, a better alternative would be to enhancing the signal. Because noise is centered in the low frequencies, it tends to mask the high frequency signal. By moving 
the microphone of a hearing aid deeper into the ear canal, we are able to enhance the signal, thereby, improving speech understanding.

The individual variability in speech understanding across subject performance, led us to adopt the methods used in Chmiel and Jerger's (1995). Using this research design allowed for a condition in which the performance of a few subjects could estimate the performance of a specified population. 
Chapter 3

Methods

In an attempt to examine the effect of microphone placement on understanding speech in noise, five individuals with sensorineural hearing loss were evaluated. Under standard TDH-39 headphones, the subjects listened to speech samples recorded through three hearing aid systems against a background noise of multi talker babble. A single subject design was employed to investigate individual differences across the different hearing aid configurations.

\section{Subjects}

Case 1: MG is a 62-year-old male with a moderate to severe bilateral sensorineural loss. Figure 1 shows his audiogram. MG has been a successful user of ITE hearing aids for 14 years.

Case 2: $\mathrm{HH}$ is a 73-year-old male with a severe to profound bilateral sloping sensorineural loss. Figure 2 shows his audiogram. $\mathrm{HH}$ has been a successful user of ITE hearing aids for 10 years.

Case 3: JG is a 57 year-old female with a mild, bilateral high frequency sensorineural hearing loss. Figure 3 shows her audiogram. JG has never worn hearing aids.

Case 4: JE is a 68 year-old female with a mild to moderate flat bilateral sensorineural hearing loss. Figure 4 shows her audiogram. JE has worn ITE hearing aids in both ears for 3 years. 


\section{Figure 1 - Audiometric Configuration for subject 1}
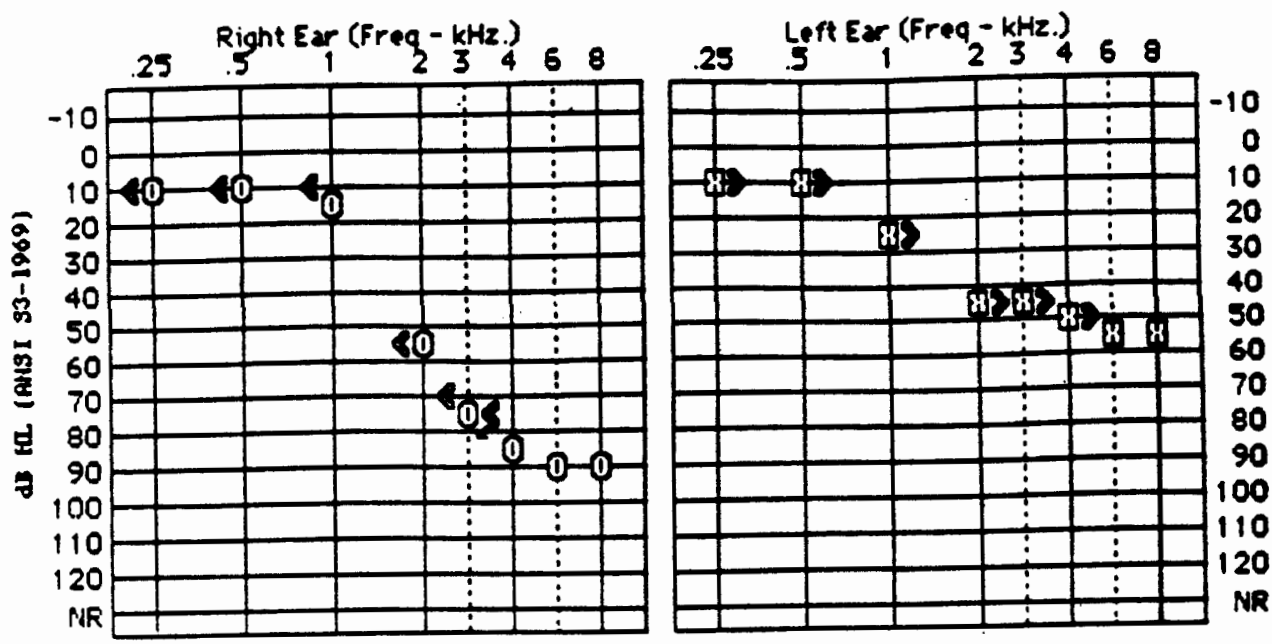

Figure 2 - Audiometric Configuration for subject 2
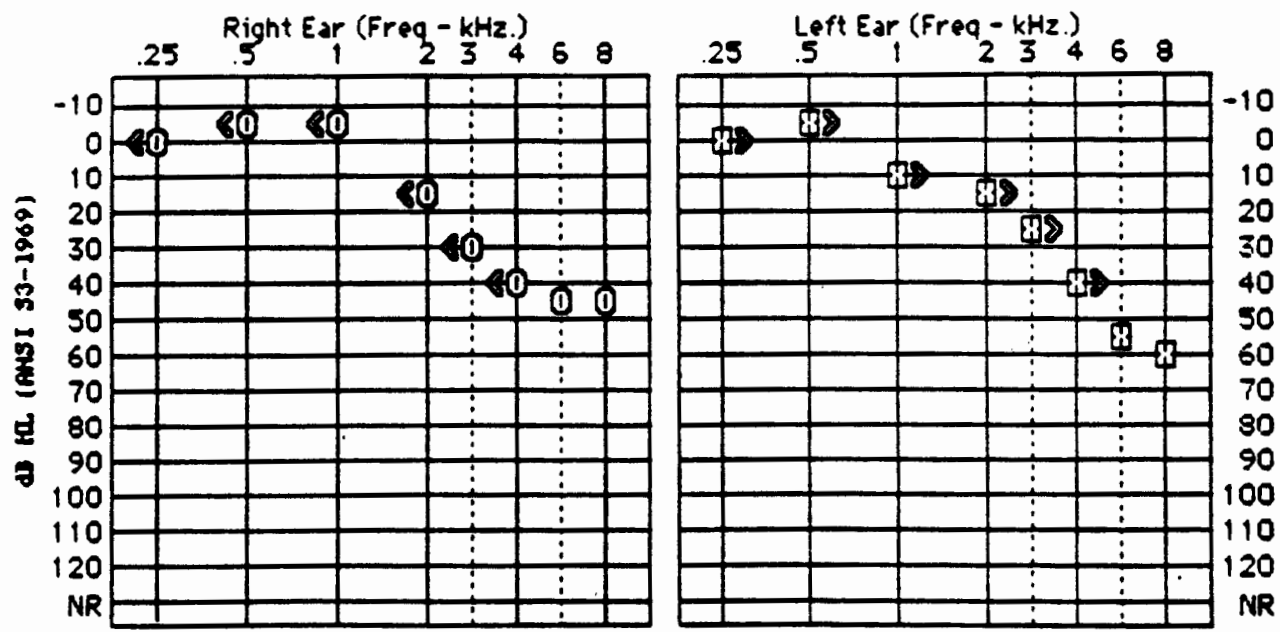
Figure 3 - Audiometric Configuration for subject 3
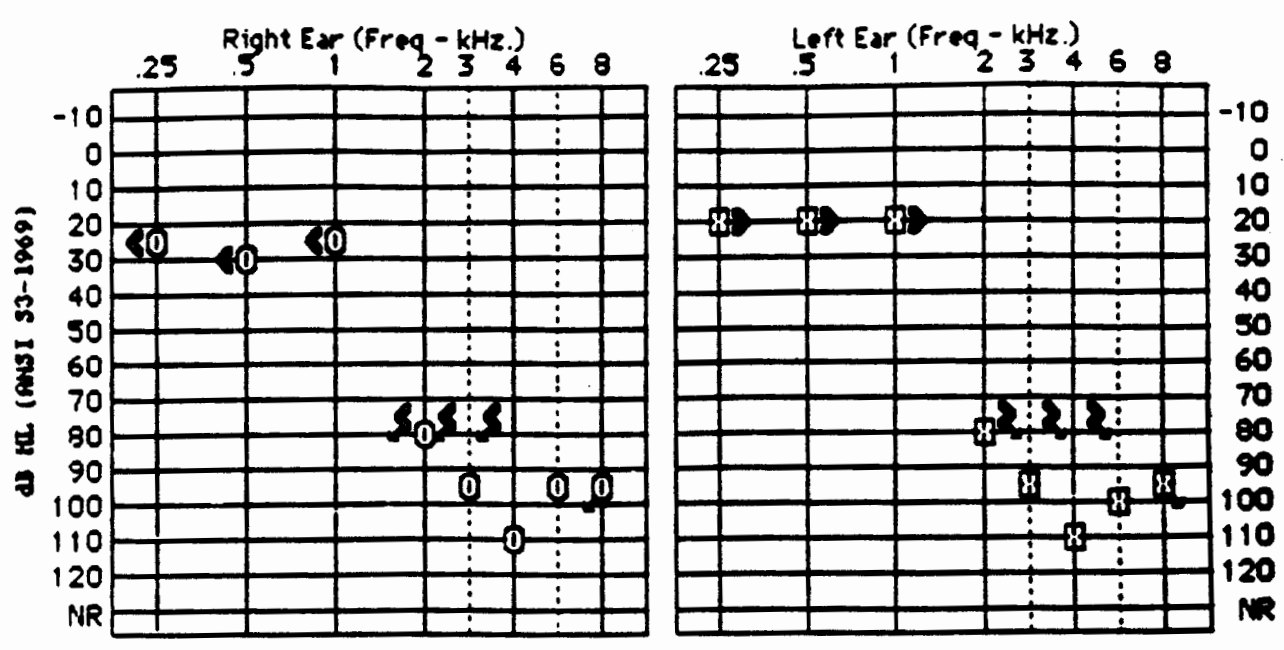

Figure 4 - Audiometric Configuration for subject 4

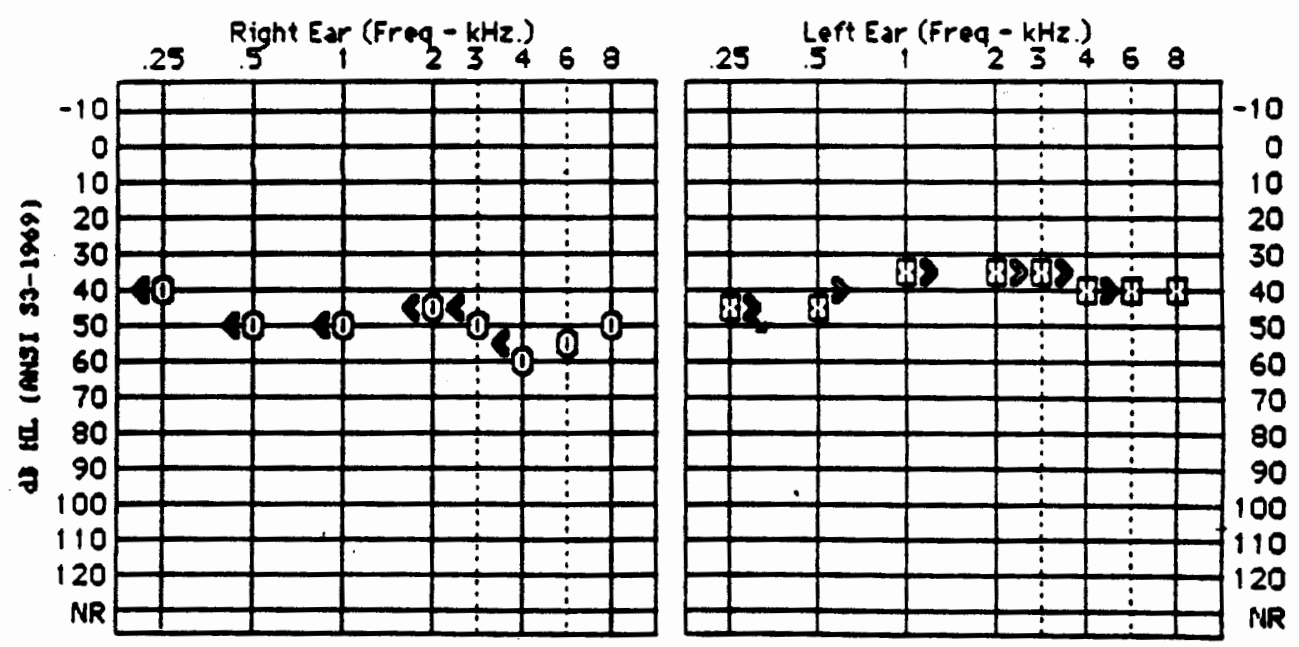


Case 5:

GG is a 30 year-old male with a mild to moderate flat bilateral sensorineural hearing loss. Figure 5 shows his audiograms. GG has worn hearing aids since the age of 4 as a result of a high fever and is currently wearing ITC hearing aids in both ears.

\section{Instrumentation}

Hearing Aids

Starkey Laboratories provided three hearing aids, equipped with a Sequel circuit, for use in this study. The Sequel is a low-noise, low-distortion amplifier circuit. An in-the-ear (ITE), in-the-canal (ITC) and completly-in-thecanal $(\mathrm{ClC})$ were designed and constructed to be identical electrically with the only difference in the hearing aids being in the placement of the microphone. An ITE was built to fill the concha, an ITC was built to fill half of the concha and the $\mathrm{CIC}$ was built to fill only the external opening of the ear canal, leaving the concha unoccluded. To control for the effects of residual volume between the tip of the hearing aid and the tympanic membrane, all hearing aids were built with a long canal terminating $4 \mathrm{~mm}$ from the end of the coupler. Each hearing aid was custom fit to Knowles Electrical Mannequin for Acoustic Research (KEMAR)'s left ear. Figure 6 shows the coupler responses of the three hearing aids.

\section{Test Tapes}

The stimulus materials used in this study were recorded through three different hearing aid conditions on KEMAR. KEMAR's left ear was fit with the 
Figure 5 - Audiometric Configuration for subject 5

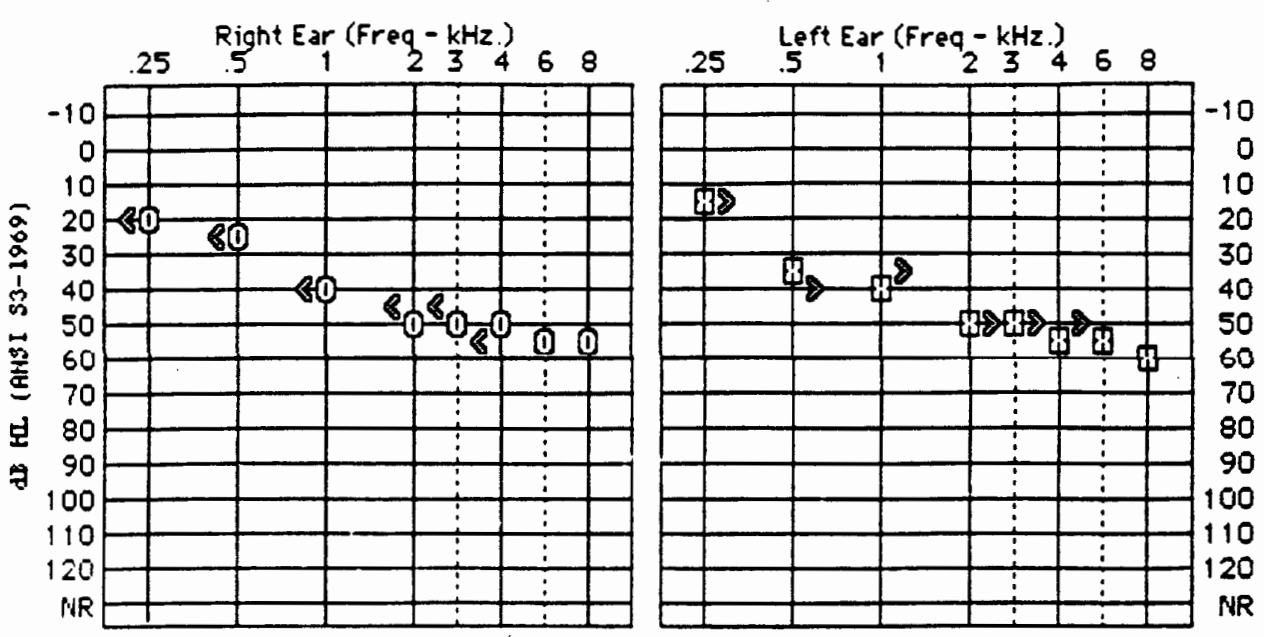




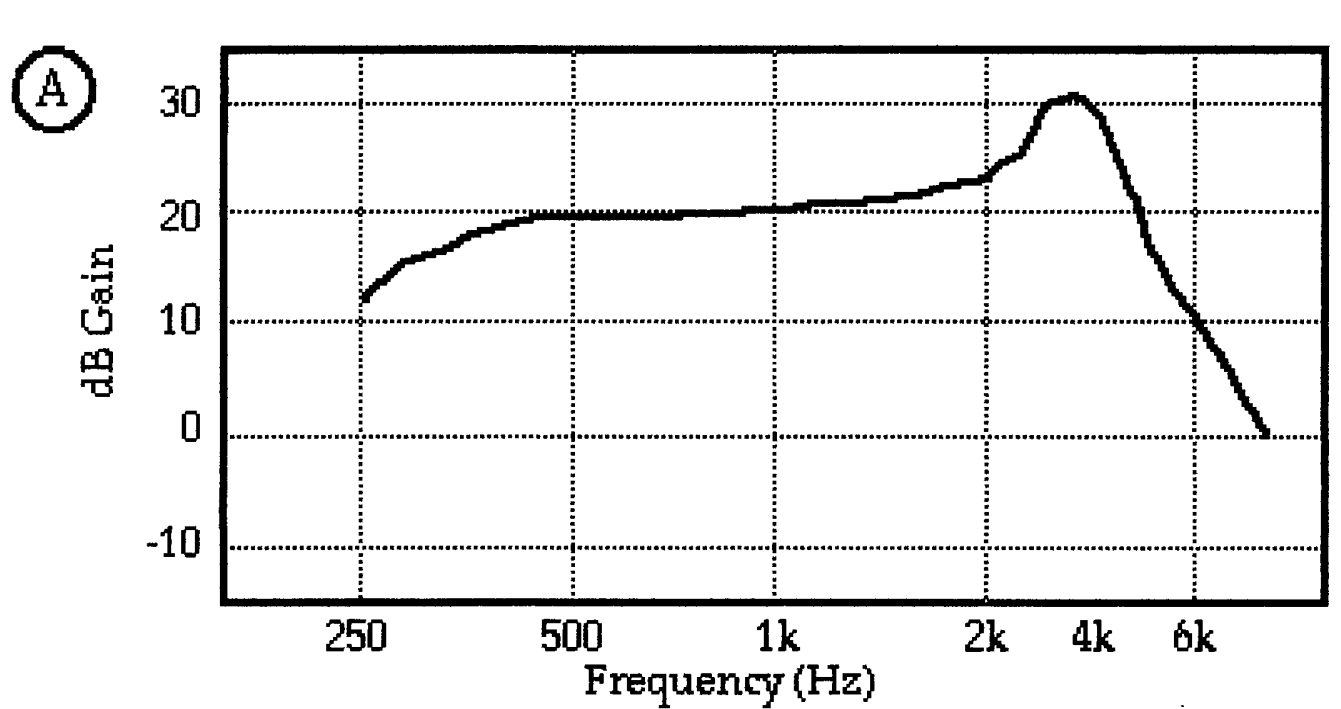

32
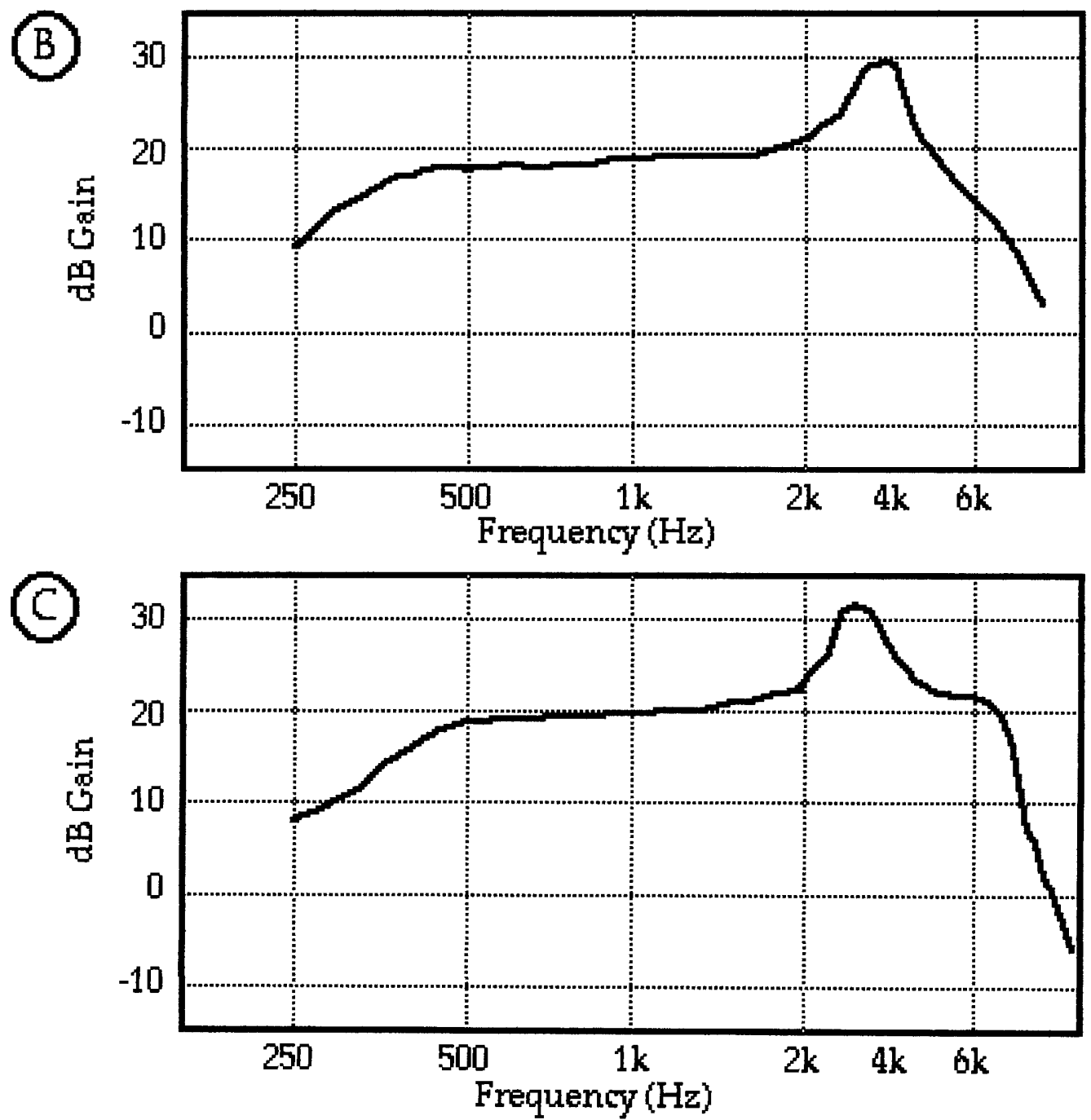

Figure 1. 2cc coupler frequency response curves for the CIC (A), ITC (B), and ITE (C) hearing aids used in this study. 
hearing aids and the output of the aids was routed, via a pre-amplifier to a Sony Digital Audio Tape (DAT) recorder. An ACO 7013 Pacific pressure microphone was fitted to a Zwslocki coupler placed in KEMAR;s ear. The microphone was interfaced with an ACO 4012 Pacific pre-amplifier. For calibration purposes, the pre-amplifier was coupled to a Larson-Davis 812 integrating sound level meter (SLM) via a Larson-Davis AD055 adapter. The recording was completed in a $6^{\prime} \times 6^{\prime}$ sound chamber.

A tape recording of the California Consonant Test (CCT) from Auditec of St. Louis was used for the speech stimuli. Stimuli wer delivered to a Procton tape player which was connected to an NAD 2240PE stereo power amplifier. The output of the amplifier was attenuated by a Leader LAT-45 attenuator. The CCT words were delivered through a Realistic speaker which was placed at $315^{\circ}$ azimuth, one meter from KEMAR's left ear.

A Sony tape player from which the multi-talker babble was delivered was connected to a Crown D-75 equalizer, then attenuated by a Leader LAT- 45. The signal was delivered through a Realistic speaker which was placed at $225^{\circ}$ azimuth, one meter from KEMAR's left ear.

Play-back level was set in reference to the $1000 \mathrm{~Hz}$ calibration tone recorded at the beginning of each tape for both the CCT and the mulitalker babble. The level of the calibrated tone was set at $85 \mathrm{~dB}$ SPL and the noise was set at $75 \mathrm{~dB} S P L$, resulting in a $10 \mathrm{~dB}$ signal-to-noise ratio as measured by the Larson-Davis 812 integrating SLM.

The output of the hearing aids were adjusted using the volume control to produce an output of $85 \mathrm{~dB}$ SPL in response to the CCT calibration tone. The calibration tones from the CCT and the multi talker babble were used to equate the response of the hearing aids at $1000 \mathrm{~Hz}$. The output of the aids 
were equalized at $1000 \mathrm{~Hz}$ with the expectation that any differences in output (due to microphone location effect) would be evident at higher frequencies.

Thirty words from the CCT were recorded for each of the three hearing aid conditions. The words were recorded onto digital tape and imported to and stored on a Macintosh computer as sound files. The files were digitized with a $22 \mathrm{kHz}$ sampling rate and 16 bit resolution.

\section{Procedures}

The subjects were seated in the center of a sound-treated room. The stimuli were converted to an analog signal using standard Macintosh digitization hardware. The signals were routed to a GSI-16 audiometer and the stimuli were then delivered binaurally to the subject through TDH-39 headphones at a level of $50 \mathrm{~dB}$ SL re: SRT.

The subjects were seated in front of a Macintosh Centris 610 computer with an Edmark Touch screen. Instructions that described the task and assured the subject's ability to perform the task were presented on the computer screen. The pace of the stimulus presentation was under the individual subject's control.

For each hearing aid condition, 30 stimulus items were presented for a total of 90 targets items. Using techniques similar to Jerger and Chmiel (1995), the specific items were presented in blocks of 10 targets each resulting in 9 stimulus blocks. Across the three treatment conditions the order in which the blocks were presented was random with the constraint that no condition was presented more than twice in succession. 
Data Analysis

In order to determine performances differences across the three hearing aid configurations from within a single-subject design, each subject's performance was compared in a pairwise fashion between the hearing aid configurations. In other words, the performance in the ITE condition was compared to the performance in the ITC condition, the performance in the ITC condition was compared to that of the CIC condition, and the ITE and CIC conditions were compared. The analysis was completed using the Randomization Test described by Edgington (1987) and Barlow and Hersen (1984).

The Randomization Test is a non-parametric analysis tool which allows for estimation of a population distribution from a single subject's scores. This is accomplished by first breaking the total number of observation intervals for each treatment variable into a predetermined number of stimulus blocks. For this study, the three different hearing aid configurations represented the treatment variables. A total of 30 stimulus items were administered in each of the three treatment conditions for a total of 90 observation intervals. The 30 stimulus items for each hearing aid configuration were arbitrarily broken into blocks of 10 items. Thus, each subject was presented 9 blocks of 10 stimulus items each. The order in which these blocks were administered to the subject was random with the one stipulation that no more than 2 stimulus blocks from a single hearing aid configuration could be presented in succession.

Following administration of the stimulus items, the percentage of stimulus items correctly identified were calculated for each block of stimuli. For each hearing aid condition a total of three scores (i.e., one for each 
stimulus block) were determined. In order to estimate a population distribution that fit these observed scores, the Randomization Test protocol requires that the scores for the treatment conditions being compared, be permutated into all possible combinations. In this study, pairwise comparisons were made between the different hearing aid conditions. For each hearing aid comparison the total number of permutations were calculated as 6 ! (i.e., the total number of stimulus blocks in the comparison) divided by 3 ! times 3 ! (i.e., the number of blocks over two treatments). Thus, a total of 20 permutations were available for each subject for each comparison.

The next step in this process involved calculating means for the scores in each condition for each of the 20 permutations and then determining the difference between the means for the two conditions for each of the 20 permutations. This step provided the estimated population distribution for the subject's scores for a given comparison. The final step involved comparing the subject's actual performance (the difference between the mean scores for the two conditions being made ) against the estimated population distribution. If the subject's performance fell outside the $95 \%$ confidence interval for the estimated population distribution, the difference between the means for the two conditions is considered to be significant and, hence, represented a true performance difference. 


\section{Chapter 4}

Results

The purpose of this study was to investigate differences in word recognition performance across three different hearing aid configurations. Following the procedure described by Chmiel and Jerger (1995), a singlesubject design was adopted with each subject's performance. These performances were compared in a pairwise fashion between the hearing aid configurations. In other words, the performance in the ITE condition was compared to the performance in the ITC condition, which then was compared to that of the $\mathrm{CIC}$ condition, and finally the ITE and $\mathrm{CIC}$ conditions were compared.

Subject 1: $M G$ is a 62 year old male who has a severe sloping high frequency sensorineural hearing loss. In three test blocks of 10 words each, he averaged a score of $56 \%$ for the ITE condition. In the ITC condition, he responded correctly to $60 \%$ of the stimulus items. For the $\mathrm{CIC}$ condition, MG responded correctly to $50 \%$ of the stimulus items (see table 1). Analysis of comparisons between the ITE vs. ITC, ITC vs. CIC, and ITE vs. CIC conditions failed to reveal differences that exceeded the $95 \%$ confidence interval for the estimated population distribution. Thus, no significant differences across the hearing aid conditions were noted.

Subject 2: JG is a 57 year old female with a moderate sloping high frequency sensorineural hearing loss. In three test blocks of 10 words each, she responded correctly to $70 \%$ of the stimulus items in the ITE condition. In the ITC condition, she responded correctly to $66 \%$ of the stimulus items. For 
Tables

Table 1

Percent Correct for Subject 1 on the California Consonant Test

\begin{tabular}{|l|l|l|l|l|}
\hline \multirow{2}{*}{ Condition } & \multicolumn{3}{|c|}{ Block } & \multirow{2}{*}{ Mean } \\
\cline { 2 - 4 } ITE & 1 & 2 & 3 & Mean \\
\hline ITC & 70 & 50 & 50 & 56.7 \\
\hline CIC & 70 & 50 & 60 & 60.0 \\
\hline
\end{tabular}

Table 2

Percent Correct for Subject 2 on the California Consonant Test

\begin{tabular}{|l|l|l|l|l|}
\hline \multirow{2}{*}{ Condition } & \multicolumn{3}{|c|}{ Block } & \multirow{2}{*}{ Mean } \\
\cline { 2 - 4 } ITE & 2 & 3 & Mean \\
\hline ITC & 50 & 90 & 70 & 76.0 \\
\hline CIC & 60 & 60 & 80 & 66.7 \\
\hline
\end{tabular}

Table 3

Percent Correct for Subject 3 on the California Consonant Test

\begin{tabular}{|l|l|l|l|l|}
\hline \multirow{2}{*}{ Condition } & \multicolumn{3}{|c|}{ Block } & \multirow{2}{*}{} \\
\cline { 2 - 4 } & 1 & 2 & 3 & Mean \\
\hline ITE & 20 & 20 & 30 & 23.4 \\
\hline ITC & 20 & 20 & 10 & 16.7 \\
\hline CIC & 10 & 30 & 40 & 26.7 \\
\hline
\end{tabular}


the $\mathrm{CIC}$ condition, JG responded correctly to $63 \%$ of the stimulus items (see table 2). Analysis of comparisons between the ITE vs. ITC, ITC vs. CIC, and ITE vs. CIC conditions failed to reveal differences that exceeded the $95 \%$ confidence interval for the estimated population distribution. Thus, no significant differences across the hearing aid conditions were noted.

Subject 3: $\mathrm{HH}$ is a 73 year old male with a severe-profound, sloping high frequency sensorineural hearing loss. In three test blocks of 10 words each, he responded correctly to $23 \%$ of the stimulus items in the ITE condition. In the ITC condition, he responded correctly to $17 \%$ of the stimulus items. For the $\mathrm{CIC}$ condition, $\mathrm{HH}$ responded correctly to $27 \%$ of the stimulus items (see table 3). Analysis of comparisons between the ITE vs. ITC, ITC vs. CIC, and ITE vs. CIC conditions failed to reveal differences that exceeded the $95 \%$ confidence interval for the estimated population distribution. Thus, no significant differences across the hearing aid conditions were noted.

Subject 4: JE is a 69 year old female with a moderate, flat sensorineural hearing loss. In three test blocks of 10 words each, she responded correctly to $73 \%$ of the stimulus items in the ITE condition. In the ITC condition, she responded correctly to $70 \%$ of the stimulus items. For the $\mathrm{CIC}$ condition, JE responded correctly to $53 \%$ of the stimulus items (see table 4 ). Analysis of comparisons between the ITE vs. ITC, ITC vs. CIC, and ITE vs. CIC conditions failed to reveal differences that exceeded the $95 \%$ confidence interval for the estimated population distribution. Thus, no significant differences across the hearing aid conditions were noted. 
Tables

Table 4

Percent Correct for Subject 4 on the California Consonant Test

\begin{tabular}{|l|l|l|l|l|}
\hline \multirow{2}{*}{ Condition } & \multicolumn{3}{|c|}{ Block } & \multirow{2}{*}{} \\
\cline { 2 - 4 } & 1 & 2 & 3 & Mean \\
\hline ITE & 70 & 60 & 90 & 73.3 \\
\hline ITC & 70 & 70 & 70 & 70.0 \\
\hline CIC & 50 & 60 & 50 & 53.3 \\
\hline
\end{tabular}

Table 5

Percent Correct for Subject 5 on the California Consonant Test

\begin{tabular}{|l|c|c|c|l|}
\hline \multirow{2}{*}{ Condition } & \multicolumn{3}{|c|}{ Block } & \multirow{2}{*}{} \\
\cline { 2 - 5 } & 1 & 2 & 3 & Mean \\
\hline ITE & 90 & 60 & 90 & 80.0 \\
\hline ITC & 40 & 80 & 90 & 70.0 \\
\hline CIC & 50 & 60 & 70 & 60.0 \\
\hline
\end{tabular}


Subject 5: $G G$ is a 30 year old male with a mild sloping to moderate loss sensorineural loss. In three test blocks of 10 words each, he responded correctly to $80 \%$ of the stimulus items in the ITE condition. In the ITC condition, he responded correctly to $70 \%$ of the stimulus items. For the $\mathrm{CIC}$ condition, GG responded correctly to $60 \%$ of the stimulus items (see table 5 ). Analysis of comparisons between the ITE vs. ITC, ITC vs. CIC, and ITE vs. CIC conditions failed to reveal differences that exceeded the $95 \%$ confidence interval for the estimated population distribution. Thus, no significant differences across the hearing aid conditions were noted.

Summary

After analyzing the results, the five subjects utilized for this study showed considerable variability in their results. However, no significant differences were noted between any of the hearing aid conditions for any of the subjects. 
Chapter 5

Discussion and Research Implications

The results of this study demonstrated that, given this experimental protocol, microphone location on a hearing aid played no significant factor in understanding speech in the presence of background noise. In examining the results, no significant differences in scores were shown, however, there was considerable variability across the subjects. The subjects were required to listen to word lists under headphones, simulating three different hearing aid conditions. Four word options were given, from which they attempted to choose the correct response.

In analyzing these results, one possible conclusion was that microphone location did not effect speech discrimination performance in noise. There were many variables inherent in this study that may make it difficult to isolate microphone placement. In this particular study, we chose to model the environment for the individual subject using pre-recorded tapes of speech samples through the three hearing aid conditions in an attempt to quantify results.

A variable that may account for this finding pertains to the method used for measuring speech understanding. The test chosen to measure speech understanding in noise was the CCT. Our results indicated that subject four and five had the best scores using this test, however, these were the only two subjects in this study to show a flat hearing loss across the frequencies (i.e. slope from $500-2000 \mathrm{~Hz}<25 \mathrm{~dB}$ ). Perhaps this test was too difficult for individuals with high frequency hearing loss without the aid of visual cues. As the microphone moves further into the ear canal, the natural 
resonating effects of the ear canal should be inherent, thus showing an increase in improvement in speech understanding. This should be especially true for high frequency consonants. In theory, the $\mathrm{CIC}$ hearing aid should improve speech understanding in noise because of the boost in gain caused by the pinna in the high frequencies. In effect, we are attempting to quantify how microphone placement contributes to the emphasis of high frequencies, and thus speech understanding in the presence of background noise. Because the CCT test measures high frequency performance, it should be an adequate test for this particular study.

The circuit chosen for use in this study was a Starkey Sequel with a class $\mathrm{D}$ amplifier. This is a low noise, low-distortion device that may have been a factor in the final results. Instead, by using a circuit with reduced headroom such as seen with the linear class A circuit, we may have found significant differences in sound quality within the hearing aid conditions. Using this circuit may not have been an accurate representation of the population wearing hearing aids today. In the future, however, this type of circuit may be typical of the type of device worn. A difference in sound quality with the device used in this study may not be perceived because this system prevents saturation from occurring by minimizing peak clipping.

Controlling the environment by simulating the three hearing aid conditions failed to demonstrate an quantitative difference, but perhaps a qualitative study needs to be completed to determine if there is a difference between hearing aid styles and their effect on sound quality. In an informal judgment, the subjects were asked if they heard any differences between the hearing aid conditions. Most subjects felt there was a recognizable difference in the sound quality of some words over others. Unfortunately, the 
subjects were unaware of which hearing aid conditions they were listening to making it impossible to determine which condition they felt was the best.

This observation was not part of the test protocol and, therefore, it was not tracked. However, measuring speech understanding in a qualitative manner, may be a better test of improvement and, perhaps, would show a recognizable difference in subject performance.

Research Implications

Because the individual subjects felt there was a difference between the word lists, yet there was no significant differences within their scores, a quantitative evaluation of microphone placement may not have been the most accurate way to measure benefit. Instead of listening to a word list through headphones, perhaps a story, or conversation after which the subjects answered questions about the quality of sound would represent a better measure (Cox and Alexander, 1991).

Another suggestion to better measure the effects of microphone placement is to individually fit each subject with the three styles of hearing aids. In this particular study, the CCT was recorded against a background noise of multi-talker babble. The signal was sent through three different hearing aids worn by KEMAR to create the test tapes which were played to each subject. In this way, we attempted to control as many variables as possible to specifically isolate microphone placement. An attempt to manipulate the environment was made to measure the effects of speech understanding in noise as a function of microphone placement in a quantitative manner. In doing this, perhaps we lost the varying pinna effect of the individual subjects. A difference in performance may be noted if the 
subjects underwent speech testing in sound field under each hearing aid condition.

\section{Summary}

The purpose of this study was to quantify the effects of microphone placement on understanding speech in noise. By attempting to isolate this variable, we were able to determine that, within these specific parameters, there was no significant difference in the subjects' performance levels across the hearing aids. Further research is warranted to determine if a better measure exists that qualitatively defines the effect of microphone placement on speech understanding ability in hearing aid users. 
References

Agnew, J. (1994). Acoustic advantages of deep canal hearing aid fittings. Hearing Instruments, 45 (8), 22-25.

Barlow, D., \& Hersen, M. (1984). Single case experimental designs (2nd ed). New York: Pergamon.

Beck, L.B., (1983). Assessment of directional hearing aid characteristics. Audiology, 22,178-191.

Bentler, R.A., (1993). Satisfaction with Noise Reduction Circuits. American Journal of Audiology, 51-53.

Burkhard M.D., and Sachs R.M., (1975) Anthropometric manikin for acoustic research. Journal of the Acoustical Society of America (58), 214-222. In Katz, J., Handbook of Clinical Audiology (4th Ed). Baltimore. Williams and Wilkins.

Chasin, M. (1994). The Acoustic Advantages of CIC hearing Aids. Hearing Journal, 47 (11), 13-17.

Chmiel, R. and Jerger, J. (1995). Quantifying Improvement with Amplification. Ear \& Hearing. 16. 166-175.

Cox R.M., and Alexander G.C. (1991). Hearing aid benefit in everyday environments. Ear and Hearing, 12 127-139.

Cox, R.M., Alexander G.C., and Gilmore, C. (1987). Development of the Connected Speech Test (CST). Ear and Hearing, 8 (5), 199-126.

Danaher E. M., and Pickett J.M. (1975). Some masking effects produced by low frequency vowel formants in persons with sensori-neural hearing loss. Journal of Speech and Hearing Research, 18 261-271.

Dempsey J. (1987) Effect of automatic signal processing amplification on speech recognition in noise for persons with sensori neural hearing loss. Annals of Otorhinolarygology, 96, 251-253.

Duquesnoy A.J., and Plomp R. (1983). The effect of a hearing aid on the speech-reception threshold of hearing-impaired listeners in quiet and in noise. Journal Acoustical Society of America, 73, 2166-2173.

Edgington, E. (1967). Statistical inference from $N=1$ experiments. Journal of Psychology, 65, 195-199.

Edgington, E. (1987). Randomization Test (2nd Ed.) New York. Marcel Decker, Inc. 
Fabry, D., and Schum, D. (1994). The Role of Subjective Measurement Techniques in Hearing Aid Fittings. In Valente, M., Strategies for Selecting and Verifying Hearing Aid Fittings. New York. Theime Medical Publishers, Inc.

Farassopoulos, A. (1989). Speech enhancement for hearing aids using adaptive beamformers. Proceedings IEEE ICASSP, 1322-1325. In Katz, J., Handbook of Clinical Audiology (4th Ed.) Baltimore. Williams and Wilkins.

Festen J. M., and Plomp R. (1990). Effects of fluctuation noise and interfering speech on the speech-reception threshold for impaired and normal hearing. Journal Acoustical Society of America, 88, 1725-1736.

Florentine M., Buus S., Scharf B., and Swicker E. (1980). Frequency selectivity in normally-hearing and hearing-impaired observers. Journal of Speech and Hearing Research, 47, 646-669.

Fortune T., and Preves, D. (1994). Effects of CIC, ITC, and ITE Microphone Placement on the Amplification of Wind Noise. Hearing Journal, 47 (9) 23-27.

Franks J., and Beckmann N., (1985). Rejection of hearing aids: attitudes of a geriatric sample. Ear and Hearing, 6, (3) 161-166.

Gatehouse S., (1992). The time course and magnitude of peripheral acclimatization to frequency response: Evidence from monaural fitting of hearing aids. Journal Acoustical Society of America, 92, 12561268.

Gatehouse S.A., and Killion M.C., (1993). HABRAT: Hearing Aid Brain Rewiring Accommodation Time. Hearing Instruments, 44, (10). 29-32.

Givens, G.D., and Jacobs-Condit, L. (1981). Consonant identification in quiet and in noise with the normal and sensorineural hearing impaired. Journal of Auditory Research, 21, 279-285.

Glasberg B., and Moore B., (1986). Auditory filter shapers in subjects with unilateral and bilateral cochlear impairments. Journal Acoustical Society of America, 79, 1020-1033.

Graupe D., and Causey D. (1977). Method of and means for adaptively filtering near-stationary noise from speech. US. Patent 4,025,721. In Valente, M. Future Trends in Verification Strategies. New York.

Theime Medical Publishing Inc. 
Gudmundsen G.I., (1994). Fitting CIC Hearing Aids-Some Practical Pointers. The Hearing Journal 47. (11), 44-47.

Hosford-Dunn, H. A., (1996). Basic Primer for fitting CICs. Hearing Review, (3), 8-12.

Kates J.M. (1988). Acoustic effects in in-the-ear hearing aid response: results from a computer simulation. Ear and Hearing (9), 199-132.

Kamm C.A., Dirks D.D., and Bell S. (1985). Speech recognition and the articulation index for normal and hearing-impaired listeners. Journal Acoustical Society of America, (77), 281-288.

Killion M.C., (1990). A high fidelity hearing aid. Hearing Instruments, (41). 38-39.

Killion M.C. (1993). Personal communication. Etymotic Research, Elk Grove Village, IL.

Killion M.C. and Villchur E., (1993). Kessler Was Right-Partly: But SIN Test Shows Some Aids Improve Hearing In Noise. The Hearing Journal, 46. (9) 31-35.

Knowles Electronics, Inc. (1988). The Knowles Amplified Receiver. Knowles Report 10676-1. In Katz J. Handbook of Clinical Audiology (4th Ed.). Baltimore. Williams and Wilkens.

Kuk F.K., Tyler R.S., Stubbing P.W., and Bertschy M.R. (1989). Noise reduction circuitry in ITE instruments. Hearing Instruments, 40, (7), 2026.

Lentz W.E., (1972). Speech discrimination in the presence of background noise using a hearing aid with a directionally-sensitive microphone. In Katz, J. Handbook of Clinical Audiology (4th Ed.). Baltimore. Williams and Wilkens.

Longwell T., and Gawinski M., (1992). Fitting strategies for the 90s: Class D amplification. Hearing Journal, (45), 26-31.

Lybarger S.F., (1985). Relationship between coupler measurements of hearing aids, as required by the Food and Drug Administration (FDA) labeling regulations and the performance of an aid under actual use conditions. American Auditory Society Carhart Memorial Lecture, Atlanta. Corti's Organ. 10, No. 3. In Katz J. Handbook of Clinical Audiology (4th Ed.). Baltimore. Williams and Wilkens. 
Madison T.K., and Hawkins D.B. (1983). The signal-to-noise ratio advantage of directional microphones. Hearing Instruments, (34), 18, 24-26.

Mueller G., (1994). Small can be good too! Hearing Journal, 47 (11). 11-13.

Mueller G., (1993). A practical guide to today's Bonanza of under-used High tech hearing products. Hearing Journal, 46, (3), 13-27.

Mueller G.,H. (1995). Do Hearing Aids Work In Noise? That's A Simple Question With No Easy Answer. Hearing Journal, 48 13-26.

Nielsen L.B., Wu E., Hoffman M.W., Buckley K., and Soli S.D. (1990). Design and evaluation of FIR filters for digital hearing aids with arbitrary amplitude and phase response. Journal Acoustical Society of America, 87, (24).

Nilsson M., J., Sullivan J., and Soli S.,D. (1991) Validation of a speech intelligibility test using SRTs for hearing aid research. Journal Acoustical Society of America, 87. (24).

Nilsson M. J., Gelnett D., Sillivan J., Soli S. D., and Goldberg R. L. (1992) . Norms for the Hearing in Noise Test: The influence of spatial separation, hearing loss, and English language experience on speech reception thresholds. Journal Acoustical Society of America, 92. (385).

Northern J., Kepler L. J., Gabbard S. A., (1991). Deep canal fitting and real ear measurements. Hearing Instruments, 42, (9), 34-35, 53.

Owens, E. (1978). Consonant errors and remediation of sensorineural hearing loss. Journal of Speech and Hearing Disorders, 43, 331-344.

Owens E., and Schubert E. D., Development of the CCT. Journal of Speech and Hearing Research, 20, 463-474.

Owen A., Owen W., Pannbacker M., Middleton G., (1994). Organization and analysis of research data. In Pannbacker and Middleton's Introduction to Clinical Research in Communication Disorders. San Diego. Singular Publishing Group Inc.

Parizet E., and Polack J. (1992). The Influence of an Early Reflection upon Speech Intelligibility in the Presence of a Background Noise. Acustica, 77, 21-30.

Pavlovic, C. V., (1984). Use of the articulation index for assessing residual auditory function in listeners with sensorineural hearing impairment. Journal Acoustical Society of America, 75, 1253-1258. 
Plomp R. (1994). Noise, Amplification, and Compression: Considerations of Three Main Issues in Hearing Aid Design. Ear and Hearing. 15, 2-12.

Pollack M. C., (1987). Contemporary and Future Output-Limiting and NoiseReduction Systems. The Hearing Journal, 22-29.

Preves D. A., and Newton J. R. (1989). The headroom problem and hearing aid performance. Hearing Journal, 42. (21).

Preves D., (1993). Some Issues in Current and Future Hearing Aid technology. Audecibel, 42, 14-18.

Preves D. A., (1994). Future Trends in Hearing Aid Technology. Strategies for Selecting and Verifying Hearing Aids. New York. Thieme Medical Publishers, Inc.

Shaw E. A. G., (1974). The external ear. In Keidel W. D., Neff W. D. Handbook of Sensory Physiology. Berlin. Springer.

Skinner M. W., and Miller J. D., (1983). Amplification bandwidth and intelligibility of speech in quiet and noise for listeners with sensorineural hearing loss. Audiology. 22, 253-279.

Skinner M. (1988). Hearing Aid Evaluation. New Jersey. Prentice Hall, Englewood Cliffs,

Smriga D. (1985). Modern compression technology: Development and application-Part II. Hearing Journal, 38, (7) 13-16.

Stach B., Speerschneider J., and Jerger J., (1987). Evaluation the efficacy of ASP hearing aids. Hearing Journal, 40, 15-19 .

Stein L., and Dempsey-Hart D., (1984). Listener-assessed intelligibility of a hearing aid self adaptive noise filter. Ear and Hearing, 5, 199-204.

Stein L., McGee T., and Lewis P. (1989). Speech recognition measures with noise suppression hearing aids using single subject experimental design. Ear and Hearing. 10, 375-381.

Sullivan J. A., Allsman C. S., Nielsen L. B. and Mobley J. P. (1992). Amplification for listeners with steeply sloping, high-frequency hearing loss. Ear andHearing, 13, 35-45.

Sweetow R. (1989). ASP circuitry yields "less tinny" Results. Hearing Instruments, 40, (2) 44.

Shaw L. A. G. (1974). The external ear. In Keidel W. D., Neff W. D. Handbook of Sensory Physiology. Berlin. Springer. 
Soli S. D., and Nilsson M. J. (1994). Assessment of communication handicap with the HINT. Hearing Instruments, 45 (2), 12-16.

Sullivan R., (1989). Custom canal and concha hearing instruments: A real ear comparison. Hearing Instruments, 40. (4) 23-29, 60 .

Sung G. S., Sung R. J., and Angelelli R. M. (1975). Directional Microphone in Hearing Aids. Effects on Speech Discrimination in Noise. Archives of Otolaryngology. 101, 316-319.

Teder $H$. (1991). Hearing instruments in noise and the syllabic speech-tonoise ratio. Hearing Instruments, 42. (2) 15-18.

Van Summers W., Pisoni D. B., Bernacki R. H., Pedlow, R. I., and Stokes M. A., (1988). Effects of noise on speech production. Acoustic and perceptual analyses. Journal Acoustical Society of America, 84, (3), 9.

Van Tasell D., Larsen S., and Fabrey D. (1988). Effects of an adaptive filter hearing aid on speech recognition in noise by hearing impaired subjects. Ear and Hearing, 9, 15-21.

Vass W. K., Mims L. A. (1993). Exploring the deep canal fitting advantage Hearing Instruments, (44), 26-27.

Verschuure J., and van Benthem P.P. G. (1992). Effect of hearing aids on speech perception in noisy situations. Audiology, 31, 205-221.

Villchur E., (1973). Signal Processing to Improve Speech Intelligibility in Perceptive Deafness. Journal Acoustical Society of America, 53.

1646- 1657.

Walden B. E., Schwartz D. M., Williams D. L., Holum-Hardegen, L. L. and Crowley J. M., (1983). Test of the assumptions underlying comparative hearing aid evaluations. Journal of Speech and Hearing Disorders, 48, 264-273.

Weiss, M. (1987). Use of an adaptive noise canceller as an input preprocessor for a hearing aid. Journal of Rehabilitation Research and Development, 24. (4), 93-102.

Widrow B., Glover J., McCool J., (1975). Adaptive noise canceling: principles and applications, in Proceedings of the IEEE Conference on Acoustics, Speech and Signal Processing. In Valente M., Strategies for Selecting and Verifying Hearing Aid Fittings. New York. Theime Medical Publishers: 
Wolinsky S., (1986). Clinical assessment of a self-adaptive noise filtering system. Hearing Journal, 39, 29-32. 